Casos e Working Papers

\title{
Relações Estado, sociedade e mercado subjacentes aos padrões de organização estatal e o futuro da reforma administrativa
}

\author{
Assis Mafort Ouverney*
}

As reformas administrativas implementadas nas últimas décadas têm centrado sua atenção em estratégias de redução do tamanho do Estado e na busca de ferramentas de maior potencial de racionalização dos recursos públicos, capazes de tornar o Estado mais flexível, dinâmico e eficiente. Nesse sentido, três aspectos podem ser observados claramente: a pretensa incapacidade do Estado de promover o desenvolvimento, o exagerado papel atribuído ao mercado como modelo de eficiência e a negligência quanto ao papel a ser desempenhado pela sociedade nas decisões desse novo Estado. Como resultado, multiplicam-se na literatura análises sobre a eficiência e a efetividade do aparelho administrativo estatal que ignoram o desenvolvimento de suas relações com o mercado e a sociedade civil. Dessa perspectiva, este ensaio procura analisar a influência da evolução do padrão de relações entre Estado, sociedade e mercado durante o século XX na concepção do que seja uma ação estatal eficiente. Na conclusão, aponta possibilidades para próximas estratégias de revisão da reforma do Estado.

No final da década de 1920, os fenômenos econômicos que culminaram com a crise de 1929 trouxeram elementos empíricos que evidenciaram a insuficiência do paradigma liberal de funcionamento do sistema econômico. Apesar da queda significativa dos salários na segunda metade daquela década, o desemprego atingia níveis surpreendentes em relação aos verificados até então nas economias industrializadas, indicando que as livres forças de mercado pareciam incapazes de conduzir o sistema econômico às condições indispensáveis ao crescimento e ao emprego da força de trabalho.

O acirramento da crise fez surgirem concepções teóricas que romperam com a tradição liberal, ao defenderem o ponto de vista de que a depressão fora causada pela insuficiência de demanda agregada. Tal concepção foi postulada por Keynes e estabelecia um novo paradigma econômico, onde o Estado passa a representar o elemento responsável pelo pleno emprego da economia através da expansão dos gastos via política fiscal. Assim, era estabelecida uma nova forma de ação governamental que se caracterizava pelo intervencionismo econômico, no qual o Estado também passava a atuar na esfera produtiva, através de empresas estatais, não apenas em países industrializados, mas também em nações em industrialização (de forma mais acentuada), como no caso do Brasil a partir da década de 1930 .

Além da ativa atuação no sistema econômico, o Estado vinha desenvolvendo desde o final do século XIX, novas relações com a sociedade civil, que resultaram na formação e posterior consolidação no período pós-II Guerra Mundial, de sistemas de proteção social que, não obstante a diversidade de formas assumidas nos diferentes contextos nacionais, convencionou-se chamar de Estado do Bem-Estar Social (Welfare State). Foram estabelecidos assim, sistemas e políticas públicas que visavam consolidar certo grau de proteção governamental em domínios como renda, saúde, habitação e educação, cujo acesso é direito integrante do processo de construção da cidadania.

Na concepção de Esping-Andersen (1995), a formação dos sistemas caracterizados como Estados do BemEstar Social representa um desenvolvimento além do simples aperfeiçoamento de políticas sociais existentes. De forma geral, pode-se afirmar que a emergência e a consolidação dos sistemas de proteção social característicos do Estado do Bem-Estar Social consistem num conjunto de ações governamentais desenvolvidas

* Mestrando em Administração Pública pela EBAPE/FGV. E-mail: assismafort@ fgvmail.br. 
em resposta a processos de modernização em contextos de formação de Estados nacionais, visando à garantia de direitos aos cidadãos.

A organização interna do Estado que sustentou até a década de 1970 a crescente atuação governamental nas áreas econômica e social estava estabelecida desde o final do século XIX, e fora construída com base nos princípios sistematizados pelo sociólogo alemão Max Weber; por isso conhecida como burocracia weberiana. O modelo burocrático foi implantado em substituição ao patrimonial, típico dos Estados absolutistas, onde inexistia a distinção entre os negócios públicos e os privados. O Estado burocrático mostrou-se superior ao patrimonial, característico de governos patriarcais e personalistas, permitindo a administração de funções e questões de maior complexidade, trazidas pela agenda do sistema capitalista, a partir de meados do século XIX.

A burocracia buscava a racionalidade do processo produtivo, calcada em princípios como impessoalidade, neutralidade e meritocracia, para citar os mais importantes. Fountain (2001) resumiu as características do modelo burocrático na forma de um tipo ideal (racional-legal), tal como concebido por Weber:

- estabelecimento de áreas de competência jurisdicional (administração por funções delimitadas por normas legais e exercidas por pessoas qualificadas);

- hierarquia que significa a supervisão das instâncias inferiores pelas superiores;

- registro escrito de informações e processos, preservados e arquivados em sua forma original;

- treinamento prévio especializado para exercício da função;

- dedicação exclusiva à função exercida; e

- estabelecimento de regras gerais e impessoais de funcionamento dos processos.

A continuidade dessa relação Estado-sociedade-mercado ficou inviável a partir da década de 1970, em virtude de transformações verificadas nos mais diversos aspectos da sociedade. O surgimento de novas tecnologias de produção (como a informática) e a automação desencadearam a Terceira Revolução Industrial, rompendo com o padrão fordista-taylorista vigente, flexibilizando o processo produtivo e possibilitando sua ampla articulação internacional, através de redes produtivas comerciais e financeiras integradas em tempo real. Tal processo desencadeou o fenômeno conhecido como globalização, uma etapa singular na história humana, onde novos sistemas de infra-estrutura e comunicação possibilitaram a circulação de pessoas, mercadorias, serviços e meios financeiros, além do intercâmbio de padrões sociais e culturais, de modo sem precedentes.

Além dessas transformações socioeconômicas que resultaram da mudança do padrão tecnológico e produtivo, a disparada dos preços do petróleo registrada a partir da crise de 1973 desencadeou uma série de realocações no contexto macroeconômico mundial que aprofundaram o sentimento de crise. O ciclo de crescimento econômico registrado nas décadas de 1950 e 1960 foi reduzido a um contexto marcado por desemprego, redução de salários e lucros, queda da atividade econômica e dos investimentos, juros elevados e crescente processo inflacionário, tanto nas economias avançadas como nos países em desenvolvimento.

Um terceiro fator importante nessa redefinição da relação Estado-sociedade-mercado ocorrida a partir de meados da década de 1970 foi a incapacidade do Estado de manter o padrão de gastos sustentado por uma política fiscal expansionista, por causa tanto da queda de receitas resultante da crise do petróleo, quanto do crescente e insustentável endividamento público.

A combinação dessas transformações estruturais forçou a redefinição não só da forma de organização, como também do papel do Estado nas áreas econômica e social. Segundo Abrúcio (2001, p.177), "surgia naquele momento, não só um Estado com menos recursos, mas um Estado nacional com menos poder". Na esfera econômica, ao contrário do ocorrido na década de 1930, o keynesianismo foi considerado ineficaz como parâmetro de condução da economia e substituído por princípios neoliberais que postulavam a desregulamentação do mercado, a retirada completa do Estado como agente produtor da economia, além da redução dos gastos e do endividamento público, sob a alegação de que induziam a processos inflacionários e ao crescimento das taxas de juros reais da economia. 
Na esfera social, pela limitada base fiscal pública e crescente demanda por programas sociais gerada pelo desemprego e pelo envelhecimento populacional, o Estado se tornou incapaz de ampliar, ou mesmo sustentar, de acordo com os padrões do pós-guerra, os sistemas de proteção social característicos do welfare state. Esping-Andersen (1995) resume os diagnósticos sugeridos na literatura sobre a crise do Estado de Bem Estar em três linhas principais:

- argumentos relacionados a distorções de mercado que concebem as políticas de welfare como indutoras do desemprego voluntário, da redução de poupança e dos investimentos, entendendo deste modo que o Estado de Bem Estar é uma das causas de sua própria crise;

- argumentos relativos à catástrofe do envelhecimento populacional, ignorando a possibilidade de se evitar crises por meio de decisões políticas sobre a composição demográfica da população e sobre fatores relativos à produtividade do trabalho;

- argumentos concernentes às consequiências da globalização da economia, sob a alegação de que esse processo é seletivo e desfavorável aos países que destinam mais recursos para a proteção social ou são menos competitivos em virtude da maior incidência de contribuições sociais sobre o custo do trabalho.

Além das transformações de ordem econômica e social, as mudanças na relação Estado-sociedade-mercado atingiram a própria organização interna do Estado instituída sobre as bases do modelo burocrático weberiano. Essas mudanças tornaram-se um dos principais pontos, senão o principal ponto da reforma, a partir do momento em que se estabeleceu um novo consenso neoliberal e conservador na maioria dos países desenvolvidos (EUA, Grã-Bretanha, Suécia, Nova Zelândia e Austrália, entre outros) a partir do final da década de 1970.

No caso brasileiro, os três aspectos mencionados no início deste ensaio como características essenciais das recentes reformas administrativas se tornam mais acentuados e merecem, em especial, uma reflexão que considere o rumo tomado pelas relações entre o Estado, a sociedade civil e o mercado ao longo do século XX.

Uma das características da formação do Estado nacional brasileiro é a centralização resultante de um processo histórico no qual o Estado precedeu a nação (CAMARGO, 1992). Do mesmo modo, a condição de economia primária-exportadora, característica de um país colonial, exigiu do Estado um papel preponderante na condução do processo de industrialização.

Esses dois aspectos se tornaram extremamente visíveis como fatores basilares da primeira reforma administrativa brasileira, desenvolvida por Getulio Vargas durante as décadas de 1930 e 1940 . A constituição das estruturas estatais de condução das políticas públicas nacionais, centralizadas no Executivo federal, significou a implantação no Estado brasileiro do modelo burocrático weberiano, e a criação Departamento Administrativo do Serviço Público (Dasp) foi a maior expressão disso. Assim, a busca por maior eficiência e racionalização dos recursos, num país ainda agrário e sob regime autoritário, imprimiu à primeira reforma administrativa brasileira, bases de relacionamento do Estado com o mercado e a sociedade civil bastante diferentes das que sustentam as reformas atuais. Como resultado, surgiu um Estado cuja identidade relacionava eficiência com capacidade de promoção do desenvolvimento, numa relação assimétrica com o mercado, uma vez que este fora incapaz de estabelecer as bases materiais formadoras de uma economia industrializada, pela ausência de uma revolução burguesa nos moldes clássicos ocidentais (FERNANDES, 1976). Portanto, em relação ao mercado, o Estado “(...) com autonomia, força e capacidade de iniciativa, (...) planejou, regulou e interveio (...), e tornou-se ele próprio produtor e empresário" (DRAIBE, 1985, p.20).

A formação das bases sociais de sustentação do regime autoritário do Estado Novo, apesar dos avanços com a incorporação de setores urbanos antes excluídos, implicou o estabelecimento de formas mais acentuadas de controle social, fundamentadas em padrões de representação de interesses corporativos que substituíram as formas e articulações anteriormente estabelecidas. Portanto, em relação à sociedade civil, na criação de instituições nacionais e centralizadoras, o Estado "regulou as relações sociais, absorveu no interior de suas estruturas os interesses sociais (...). Debilitou as instituições representativas e solapou as formas autônomas de aglutinação e expressão de interesses e conflitos" (DRAIBE, 1985, p.20). 
A chamada segunda reforma administrativa, ocorrida nos anos 1960, surgiu da necessidade de consolidar e aprofundar o processo de industrialização associado ao capital externo, iniciado nas primeiras décadas do século XX, o que exigiu a instituição de condições especiais para a ampliação do papel do Estado como produtor e empreendedor. $\mathrm{O}$ estabelecimento de um regime autoritário-burocrático representou um rompimento com o período democrático restabelecido em 1945 e foi o imperativo político dessa nova etapa.

A instauração de novas agências da administração indireta - como autarquias, fundações e sociedades de economia mista - e a edição do Decreto-lei n ${ }^{0}$ 200/67 significaram a reformulação das estruturas administrativas, visando à maior agilidade e eficiência não conseguidas com o modelo estritamente burocrático da primeira reforma. Segundo Fleury (1997, p.301) a “(...) reforma dos anos 1960 representou a possibilidade de romper com os entraves burocráticos que cerceavam o aprofundamento da expansão do capitalismo associado - já que os políticos haviam sido liquidados em 1964 - de forma a permitir que, com a presença do Estado na área econômica, fosse completado o ciclo de substituição de importações iniciado os anos 1930".

Assim, neste segundo redimensionamento do aparelho de Estado, resultado da mudança de forças políticas e econômicas, foi reafirmado seu potencial como ator central na coordenação econômica ante o mercado e na construção e implementação de um projeto desenvolvimentista e nacionalista. Embora nesse novo momento da economia brasileira a empresa estrangeira tenha assumido lugar relevante junto com a empresa nacional - esta como produto de uma economia em industrialização e diversificada - o mercado era considerado uma instância promotora do desenvolvimento ainda limitada, tendo em vista que o terceiro componente do tripé, a empresa estatal, era quem capitaneava o novo projeto.

Contudo, a segunda reforma administrativa foi extremamente excludente, marcada por uma desarticulação dos canais de representação dos interesses da sociedade no acesso ao processo decisório do Estado, mesmo os de constituição corporativa. As instâncias estratégicas de condução do país se tornaram reservadas à tecnoburocracia, ou eram atingidas apenas por formas pouco coletivas, tais como "anéis burocráticos", aos quais somente frações da classe dominante, beneficiárias do regime, tinham acesso (CARDOSO, 1977). Nesse sentido, as relações entre Estado e sociedade na segunda reforma administrativa brasileira foram pautadas pelo impedimento da participação da sociedade no processo decisório das políticas públicas.

As transformações socioeconômicas e políticas ocorridas no país desde o final da década de 1970, em diversas ocasiões, trouxeram à tona propostas de reformulação da máquina do Estado. A combinação das crises econômica e fiscal com a transição para o regime democrático proporcionou várias oportunidades para a apresentação e implementação de reformas do Executivo federal, durante as décadas de 1980 e 1990 (MARCELINO, 2003). Tais oportunidades convergiram para o diagnóstico mais explicitamente exposto no Plano Diretor da Reforma do Estado, elaborado pelo governo Fernando Henrique Cardoso. O argumento era o de que concomitante às crises política, econômica e fiscal, aprofundava-se, como causa e conseqüência, uma crise do Estado, de sua forma de gerenciamento e de intervenção (PEREIRA, 1998).

A incapacidade de gerenciamento foi atribuída à inadequação do modelo burocrático weberiano aos desafios estabelecidos no contexto de sociedades e economias interdependentes e globalizadas. Para superar tal impasse, propôs-se a passagem da administração burocrática para a gerencial. Ao se apresentar o gerencialismo como modelo de eficiência, novamente o mercado foi assumido como parâmetro de excelência incontestável. Tratava-se, simplesmente, da aplicação de técnicas e ferramentas amplamente utilizadas na gestão empresarial em setores do Estado não incluídos no seu núcleo estratégico.

Quanto ao modo de intervenção, o paradigma das reformas administrativas das décadas de 1930 e 1960, segundo o qual o Estado era o promotor do desenvolvimento, foi tomado como vetor das crises econômicas das últimas décadas do século. Cabia então alterar a forma de inserção do Estado na economia, limitando essa interferência ao já referido núcleo estratégico e às atividades exclusivas.

Ainda que das três reformas administrativas de maior destaque, a dos anos 1980 e 1990 tenha sido a única ocorrida sob um regime democrático, a abertura de espaços para a participação da sociedade civil nas decisões de Estado não se desenvolveu de forma muito diferente das experiências anteriores. As decisões quanto ao 
direcionamento estratégico do país, bem como àquelas referentes à política econômica, continuaram sendo tomadas pelos núcleos tecnocráticos, mantendo a sociedade civil excluída desse processo.

Assim, tanto no exterior quanto no Brasil, a estratégia consistiu inicialmente em valer-se de princípios e técnicas utilizados no mercado para redefinir os fundamentos da administração pública. Segundo Abrúcio (2001, p.178), "nesse processo, o modelo gerencial, importado da iniciativa privada, foi o fio condutor das reformas, embora não exclusivo, nem tampouco imutável". Nesse sentido, as reformas se concentraram em alguns pontos principais, num processo onde se busca a total separação entre a política e a administração e cuja essência foi sintetizada por Kettl (2001) como:

- de ênfase na modificação de procedimentos;

- accountability;

- maior atenção à eficiência como resultado final;

- transferência de tarefas tradicionalmente atribuídos ao Estado para a iniciativa privada;

- concepção do cidadão como consumidor; e

- de redução das funções do Estado a núcleos mínimos não muito bem definidos.

Entretanto, diversos autores têm apontado os excessos desse modelo de reforma administrativa baseado no consenso neoliberal. Entre eles, destaca-se Evans (2003) ao propor uma análise integrada que relacione a efetividade do aparato estatal ao relacionamento deste aparato com as esferas da sociedade e do mercado. Essa análise tem como parâmetro o conceito de hibridismo, segundo o qual uma administração pública efetiva resulta da sinergia entre três elementos:

- o modelo básico de estrutura administrativa composto por normas profissionais, estruturas hierárquicas e padronização de processos;

- os mecanismos para ampliar o controle bottom-up democrático pelos cidadãos; e

- os indicadores de mercado.

De acordo com o hibridismo, repensar a reforma implica reavaliar o papel exageradamente amplo que foi assumido pelo mercado, uma distorção causada pelo consenso neoliberal.

Como visto anteriormente, de uma perspectiva histórica, torna-se claro que modelos de desenvolvimento devem ser analisados a partir dos contextos históricos nos quais estão inseridos, e não simplesmente em função das concepções ideológicas de momento. Num contexto globalizado de integração de mercados, a inserção internacional competitiva do país, a redução das desigualdades sociais e a formação de capital humano e social são essenciais para promover o desenvolvimento econômico. O padrão de relacionamento Estado-sociedademercado gerado pelas reformas implementadas nas últimas décadas, fundamentado na supremacia do mercado e na negligência do papel da sociedade civil no processo decisório, revela-se incapaz de responder aos desafios mencionados.

Embora seja reconhecida a importância da capacidade do mercado de alocar recursos, de modo eficiente, garantindo a maior competitividade das empresas, a inserção internacional num contexto globalizado não depende apenas do mercado. Ela envolve fatores de natureza socioeconômica, dos quais o mercado não consegue dar conta, como a redução das desigualdades sociais (acentuadas pela própria globalização) e a formação de capital humano pela promoção de investimentos não-lucrativos em educação, saúde e cultura, entre outros segmentos.

Do mesmo modo, a formação de capital social como variável estratégica - conforme apontado em abordagens que postulam a sociedade civil como lócus privilegiado de dotes capazes de potencializar o processo de modernização da economia - lança novas possibilidades de revisão da relação Estado-sociedade. É no âmbito da sociedade civil que está o capital social, fonte, por exemplo, das diferenças de desempenho institucional e de grau de modernização entre as regiões norte e sul da Itália, segundo Putnam (1996). Nesse sentido, uma 
reforma que deliberadamente negligencia a participação da sociedade civil não contribui para promover o desenvolvimento econômico, dissipando vias de consolidação da democracia e comprometendo, assim, um processo indispensável para a formação de capital social.

Por fim, cabe destacar a necessidade de redefinição das três tendências mencionadas no início deste ensaio numa futura revisão da reforma administrativa. O propósito é que o Estado reafirme seu potencial de promoção do desenvolvimento econômico, que a relação com o mercado seja menos assimétrica e mais convergente e que a participação da sociedade civil seja incentivada e efetivamente incorporada pelo Estado nos processos decisórios.

\section{Referências bibliográficas}

ABRUCIO, F. L. Os avanços e os dilemas do modelo pós-burocrático: a reforma da administração pública à luz da experiência internacional recente. In: BRESSER-PEREIRA, L. C.; SPINK, P. (Org.). Reforma do Estado e administração pública gerencial. Rio de Janeiro: FGV Editora, 2001. p.173-199.

BRASIL. Ministério da Administração e Reforma do Estado. Plano diretor da reforma do aparelho de Estado. Brasília: Mare, 1995.

BRESSER-PEREIRA, L. C.. Da administração pública burocrática à gerencial. In: BRESSER-PEREIRA, L. C.; SPINK, P. (Org.). Reforma do Estado e administração pública gerencial. Rio de Janeiro: FGV Editora, 2001. p. 237-270.

CAM ARGO, A. A Federação acorrentada: nacionalismo desenvolvimentista e instabilidade democrática. In: ENCONTRO ANUAL DA ANPOCS, 16., 1992, Caxambu. Anais... Caxambu: ANPOCS, 1992, p. 1-59.

CARDOSO, F. H. 0 modelo político brasileiro. Rio de Janeiro: Difel, 1977.

DRAIBE, S. Rumos e metamorfoses: Estado e industrialização no Brasil 1930-1960. Rio de Janeiro: Paz e Terra, 1985.

ESPING-ANDERSEN, G. 0 Futuro do Welfare State na nova ordem mundial. Lua Nova, n.35, p.75-111, 1995.

EVANS, P. El hibridismo como estrategia administrativa: combinando la capacidad burocrática con las señales de mercado y la democracia deliberativa. Revista del CLAD Reforma y Democracia, Caracas, n. 25, p. 7- 32, 2003.

FERNANDES, F. A Revolução Burguesa no Brasil. Rio de Janeiro: Zahar, 1976.

FLEURY, S. Reforma administrativa: uma visão crítica. Revista de Administração Pública, Rio de Janeiro, v.31, n.4, p.299-309, 1997.

FOUNTAIN, J. E. Building the virtual State. Washington: Brookings, 2001.

KETTL, D. A Revolução global: reforma da administração do setor público. In: PEREIRA, B; SPINK, P. (Org.). Reforma do Estado e administração pública gerencial. Rio de Janeiro: FGV Editora, 2001.

MARCELINO, G. F. Em busca da flexibilidade do Estado: o desafio das reformas planejadas no Brasil. Revista de Administração Pública, Rio de Janeiro, v.37, n.3, p.641-659, 2003.

PUTNAM, R. D. Comunidade e democracia. Rio de Janeiro: FGV Editora, 1996. 


\section{ANEXO}

\section{Questões para debate:}

- Qual o padrão de relações entre Estado, sociedade civil e mercado que orientou os diferentes processos de reforma administrativa abordados, no Brasil e no mundo?

- Qual a concepção de eficiência da ação estatal em cada um desses momentos de reforma do Estado? E o que você pensa a respeito dessa concepção: se correta, incompleta etc.?

- De acordo com as idéias discutidas neste texto, quais as possíveis diretrizes a serem incluídas numa futura agenda de reformas? Qual seria a principal diretriz a ser seguida? 